\title{
Finite-element-analysis of the mechanical behavior of high-frequency litz wire in flat coil winding
}

\author{
Michael Weigelt ${ }^{1}\left[\right.$ Cornelius Thoma $^{1} \cdot$ Erdong Zheng $^{1} \cdot$ Joerg Franke ${ }^{1}$
}

Received: 18 June 2020 / Accepted: 30 October 2020 / Published online: 17 November 2020

(c) The Author(s) 2020

\begin{abstract}
Numerous applications of daily life use flat coils, e.g. in the automotive area, in solar technology and in modern kitchens. One common property that all these applications share, is a flat coil made of high-frequency (HF) litz wires. The coil layout and the properties of the HF litz wire influence the winding process and the efficiency of the application. As a result, the HF litz wire must meet the complex technical requirements of the winding process and of the preferred mechanical, electromagnetic and thermal properties of the HF litz wire itself. Therefore, a reasonable configuration and optimization of HF litz wire has been developed with the help of a finite-element-analysis (FEA). In this work, it is first shown that the mechanical behavior of HF litz wire under tensile and bending stress can be simulated. Since the computational effort for modelling an $\mathrm{HF}$ litz wire at the single conductor level is hardly manageable, a suitable modelling strategy is developed and applied using geometric analogous models (GAM). By using such a model, HF litz wires can be designed for the specific application and their behavior in a winding process can be predicted.
\end{abstract}

Keywords High frequency litz wire $\cdot$ Flat coil winding process $\cdot$ Inductive power transfer system $\cdot$ Finite element analysis · LS-DYNA

\section{Introduction}

High-frequency (HF) litz wire consists of hundreds of twisted and ultra-fine single wires in a complex geometric structure.

In this work the application of HF litz wire in the winding process for flat coils of inductive power transfer (IPT) systems is going to be used as the validating example of the developed modelling technique. The coil in the primary pad side generates a magnetic field, which will induce a voltage in the coil in the secondary pad side, which allows electric power to be transferred over an air gap [1]. The shape

Michael Weigelt

michael.weigelt@faps.fau.de

Cornelius Thoma

cornelius.thoma@fau.de

Erdong Zheng

erdong.zheng@fau.de

Joerg Franke

joerg.franke@faps.fau.de

1 Institute for Factory Automation and Production Systems, (FAPS), Fürther Straße 246b, 90429 Nuremberg, Germany of the flat coil including the integrity of the HF litz wire's cross-section is strongly coupled to the efficiency of the IPT system. Furthermore, the mechanical properties of the HF litz wire have an impact on the degree of automation of the winding process. The better the mechanical properties of the HF litz wire fit to the requirements of the winding process, respectively of the IPT system, the easier an automation of the process can be realized [1].

Many approaches for the design of HF litz wire, or stranded structures in general, are analytical and mostly simplified like presented in [2,3]. A numerical approach has the potential to precisely predict the mechanical behavior of the HF litz wire based on the material parameters and the geometrical structure. Two distinct kinds of mechanical stresses, the tensile and the bending stress on the HF litz wire will be modelled with a Finite-Element-Analysis (FEA) and validated with experiments. 


\section{State of technology}

Before describing the modelling strategy, the winding process for flat coils will be characterized in detail in the following. Next chapters will present the existing approaches to the modelling of stranded structures and the need for action for a further modelling approach will be derived.

\subsection{Winding technique for flat coils}

The winding technique for flat coils is not only used to produce IPT systems using HF litz wire but is also guaranteeing the economic production of several other products in large quantities. Therefore, an analysis of similar production processes is useful. Linear winding processes, in which the wires are winded onto a rotating coil former with the help of a linear traversing wire guide, is a suitable example. The symmetric structure of the linear winding limits this process to the production of axially symmetric winding bodies. The winding process of the flat coils is comparable with this concept since the IPT systems also have an axially symmetrical structure.

Starting with flyer winding, whereby the rotation of the so-called "flyer arm" guiding a stranded structure, enables the winding of a stationary coil body. The shape of the coil body is unchangeable and rigidly connected to the coil former. Since the flyer arm performs a rotary movement with a constant distance to the coil former, only rectangular ("D") and circular ("C") flat coils can be wound. An alternative to flyer winding is linear winding, which is characterized by a rotating coil former, while at the same time the feed unit for the HF litz wire, also called winding nozzle, is fixed. Flyer winding as well as linear winding are very common to produce the "D" and "C" flat coils of e.g. induction hobs with a constant coil pitch. In contrast, by linear winding with adaptive coil formers, the shape of the coil former can be adapted to the desired coil topology during the winding process. With this winding concept, also variable winding distances are feasible. A fourth winding concept, winding on base material, sketches the winding and fixing of the HF litz wire on an adhesive base material with a special wire winding tool. The wire winding tool takes over the functions of wire guidance and the pressing of the HF litz wire onto the base material The production of a "D", "C", double-D ("DD") or homogeneous ("H") coil uses this concept. Multi-layer coil topologies, such as the double-D quadrature ("DDQ") or the bipolar ("BP") coil are also conceivable, depending on the degrees of freedom of the wire winding tool [4].

Figure 1 shows the different coil topologies with the winding concepts. Depending on the coil pitch (0 equals constant, $\mathrm{X}$ equals variable), the figure highlights the feasibility.

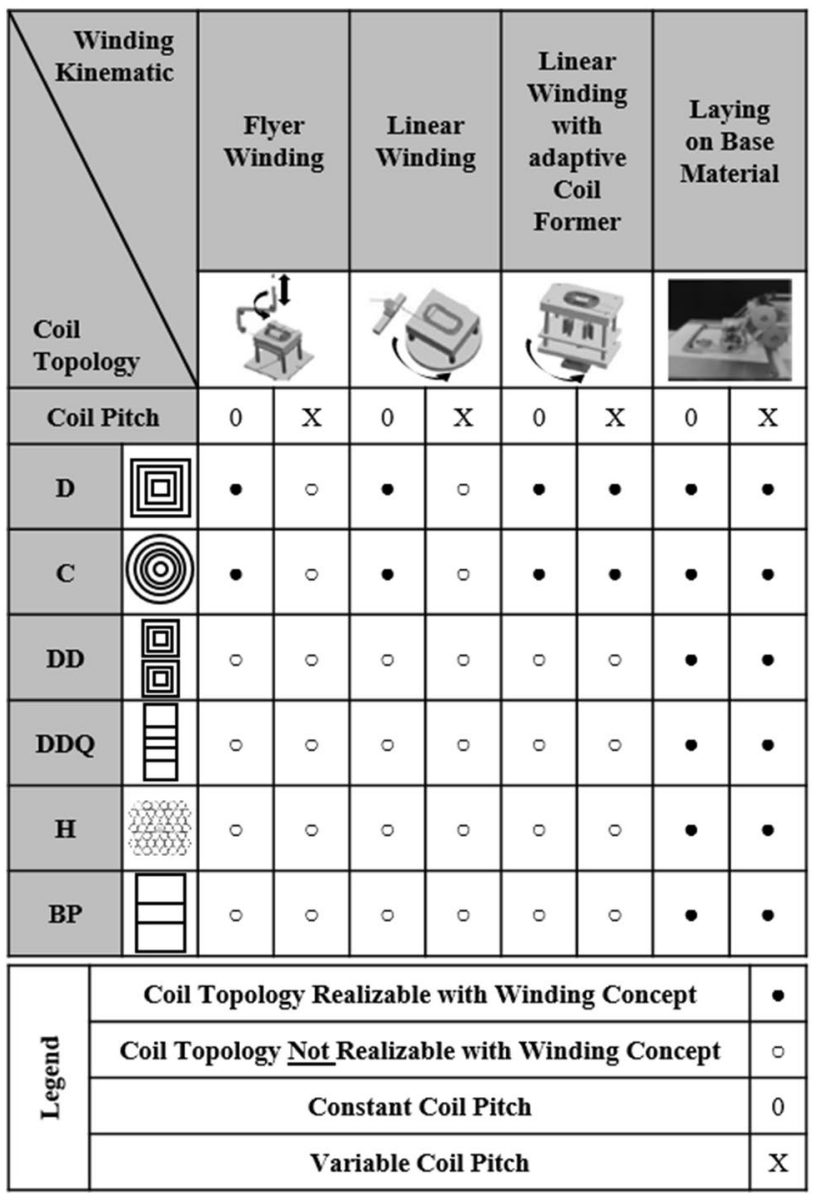

Fig. 1 Overview of different flat coil topologies and associated winding kinematics

\subsection{FEA of stranded structures}

A stranded structure is twisted over several bundling levels. The considered HF litz wire in this work consists of three bundling levels as shown in Fig. 2. The first bundling level consists of single wires is the "Bundle". The second bundling level is the "Strand", while the third level is named "Litz".

The following Table 1 shows the configuration of the HF litz wire in detail.

A simulation using the FEA is a suitable approach to validate the mechanical properties of HF litz wires and to analyze mechanical behavior of the HF litz wires in the winding process. The important parameters like tensile and pressing forces as well as the positional accuracy can be economically and efficiently predicted through a FEA [5]. In case of the HF litz wire, this means that the use of the simulation software could replace the prototypical construction of many different litz configurations and their production [6].

For those reasons, FEA has been applied for simulating the mechanical behavior of stranded structures before: 


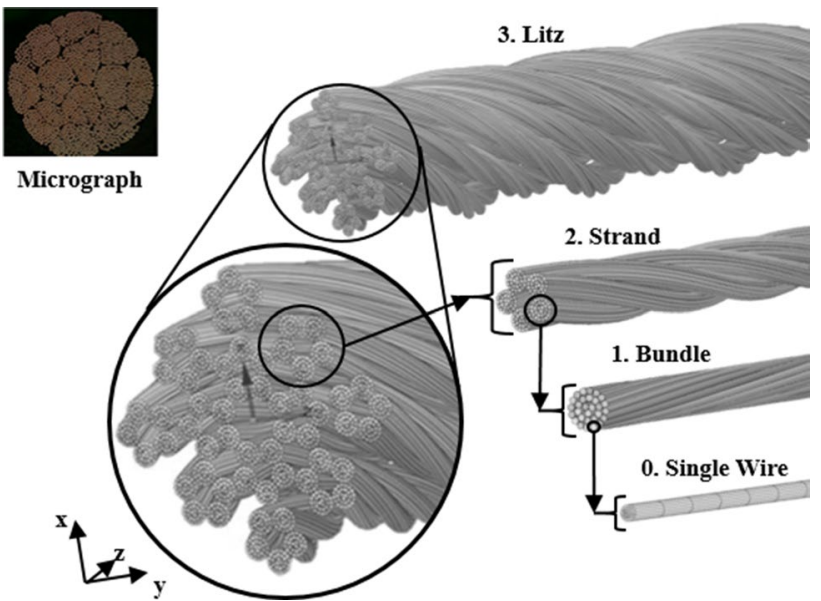

Fig. 2 Model structure of entire HF litz wire with micrograph of a cross-section

The work of Weis [7] uses FEA to determine mechanical load in axial and cross-sectional directions of wire ropes under different load scenarios. Models with detailed structures of the rope wires are constructed in CAE-software and solid elements are used for meshing. Therefore, the change in cross-sections of wire ropes and the contact situation between the wires can be accurately predicted. However, the calculation time of the simulation is exceptionally long due to the complex structure of wire ropes and the use of solid elements in meshing.

The work of Hu [8] shows a FEA of axial elastic characteristics of wire ropes. An exemplary monolayer round strand with a diameter of $20 \mathrm{~mm}$ was geometrically established in Pro/E and simulated in ABAQUS with the help of the explicit dynamic finite element method. The mesh of the stranded structure consists of approximately 1.2 million solid elements connected by approximately 1.5 million nodes. The results have shown a nonlinear behavior in the axial tension relatively to the axial elongation of the wire rope [8].

An additional approach for simulating stranded structures, especially High-Voltage (HV) litz is given in the work of Boenig [9], where the mechanical behavior of HV litz under bending and torsional loads is examined. The evaluation of the impact of implicit and explicit solvers uses simplified geometry models, different meshing methods and various friction coefficients for the contact definitions. As a result, the use of beam elements instead of solid elements for discretizing a complex geometry, like a HV litz, decreased not only the total amount of elements and nodes but also the solving time. A challenge arising with the use of beam elements is the proper calculation of the friction contacts between the beams because of their noteworthy influence on the bending stiffness of HV litz. Nevertheless, beam
Table 1 Configuration of the HF litz wire

\begin{tabular}{ll}
\hline Parameter and Unit & Value \\
\hline 0. Single wire & \\
Single wire material & CU-ETP-1 \\
Single wire diameter (mm) & 0.12 \\
Single wire insulation & \\
$\quad$ Material & Polyurethane (PU) \\
Thickness (mm) & 0.02 \\
HF Litz Wire Setup & \\
Structure & Semi-concentric \\
1. Bundle & \\
Number of single wires & 29 \\
Pitch length (mm) & 32 \\
Pitch direction & S (left) \\
2. Strand & \\
Number of single wires & $5 \times 29=145$ \\
Pitch length (mm) & 41 \\
Pitch direction & S (left) \\
3. Litz & \\
Number of core strands & 4 \\
Number of outer strands & 8 \\
Number of single wires & Bandage \\
Core pitch length (mm) & $1 \times$ PET-Foil \\
Outer pitch length (mm) & 0.023 \\
Pitch direction & 50 \\
Coating & Round \\
Kind of coating & 5.79 \\
Material & 74.6 \\
Thickness (mm) & 74.6 \\
Degree of overlap (\%) & S (left) \\
Total diameter (mm) & \\
Total diameter (incl. Coating) $(\mathrm{mm})$ & \\
\hline
\end{tabular}

elements are shown to be suitable discretization elements for long, thin wire geometries [9].

\subsection{Need for action}

So far, there is no approach to analyze a twisted multi-wire structure with over 1000 single conductors by FEA and to design it according to the application. Therefore, a closed procedure is necessary to simulate the mechanical behavior of HF litz wire under tensile and bending stresses and to detail the geometric model as much as possible considering calculation times.

Especially the HF litz wire must meet complex requirements. However, the mechanical design of an HF litz wire product is currently based on unstructured empirical values. A systematic approach to a design process is therefore necessary, in which FEA is used to support the dimensioning. A 
practical calculation time as well as the derivation of suitable substitute material models for each type of stress is crucial. Thereby material and contact nonlinearities occur due to the contact between the litz wire and coil body and the self-contacts of wires in different layers [10].

\section{FEA of the mechanical behavior of high-frequency litz wire}

The calculation uses the LS-DYNA solver for explicit time integration. The advantage of the explicit method is the great robustness of the solution even with dominant nonlinearities. For example, material nonlinearities or complex contact situations can lead to convergence problems in the implicit procedure and would require much computing time. With explicit methods, it can be solved with high reliability and an accurate estimation of the computing time [6].

\subsection{Modelling strategy}

The modelling strategy for the FEA of the HF litz wire under tensile load is executed using a bottom-up principle, as shown in Fig. 3. That means, model constructions and simulations are implemented from the lowest bundling level (single wire) to the highest level (entire litz wire) (see Fig. 2). To ensure the accuracy of the models and simulations, the calculation results are validated by the experimental results on each level. Since all models in the simulative tensile tests are constructed of several single wires, the material model for a single wire MAT-0 is applied on all bundling levels. Based on the simulation results, the material models for the geometric analogous models (GAM) on litz wire level MAT-2 can also be derived respectively (see Fig. 3).

For simulating the bending stress in a HF litz wire, a second modelling strategy has been evolved because it will be used a specific material definition of LS-DYNA that allows to define the material behavior for each kind of stress, like tensile, bending and torsional stress, independently from each other. To develop the material model of the GAM that is used for the FEA of the bending stress, the same bottomup principle was applied. This approach allows to increase the degree of detail of the geometry model. One positive effect of detailing the geometry model is that the relative movement of the single wires under bending stress is enabled. Within a simplified geometry which sums up many single wires to a GAM, the relative movement cannot be considered in the simulation model, neither in the material model. One side effect of the higher degree of detail is the increased calculation time.

The simulations are implemented in ANSYS Workbench $2019 \mathrm{R} 1 \mathrm{using}$ the LS-DYNA solver. The post processing is realized by LS-PREPOST 4.6 (see Table 2).

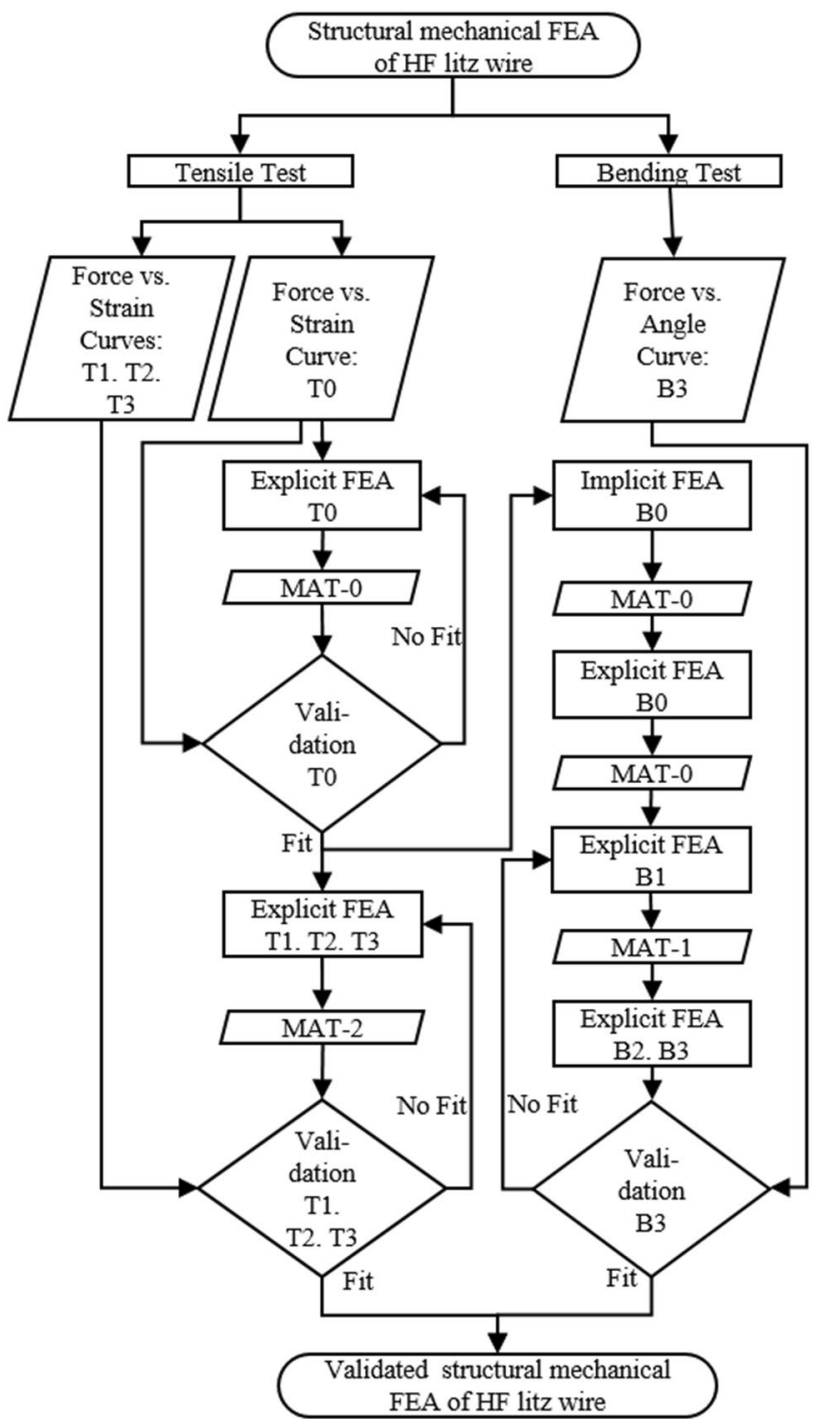

Fig. 3 Modelling strategy for the FEA of HF litz wires under tensile and bending stress

These abbreviations are used within the flow chart in Fig. 3 that illustrates the modelling strategy of the FEA of a HF litz wire.

\subsection{Tensile stress}

The tensile tests for all bundling levels are executed and evaluated according to [11]. The tensile forces and the related elongations of the test specimens are measured by a testing machine and monitored with the machine specific software. In the experiment, one end of the specimen is fixed by the clamping tool and the other end of the sample is pulled by the machine traverse.

On the single wire and bundle level, the specimens can be directly assessed. However, with a growing number of single wires and thereby increasing tensile forces, the specimens on 
Table 2 Abbreviations of evaluated structures and material models for FEA of HF litz wire

\begin{tabular}{lllll}
\hline \multicolumn{2}{l}{ Evaluated structure and material model } \\
\hline Structure & \multicolumn{2}{l}{ Tensile stress } & \multicolumn{2}{l}{ Bending stress } \\
\hline 0. Single Wire & T0 & MAT-0 & B0 & MAT-0 \\
1. Bundle & T1 & MAT-0 & B1 & MAT-1 \\
2. Strand & T2 & MAT-0 & B2 & MAT-1 \\
3. Litz & T3 & MAT-0 & B3 & MAT-1 \\
3. Litz-GAM & T3 & MAT-2 & & \\
\hline
\end{tabular}

strand and litz level slip from the clamps. To avoid slipping, both ends of the specimens are hot crimped using tubular cable lugs. As at the welding of copper, the strength of the specimens is weakened by the heat [12], which has a strong influence on the elongation of the material to failure in the tensile test. The elongations to failure on the single wire and bundle level are approx. 25\%, but the results on the strand and litz level are less than $10 \%$. Therefore, as an alternative crimping method that ensures a comparable robust crimping but at lower heat impact ultrasonic crimping can be used. Another approach to increase the friction between the ends of the specimens and the clamps can be realized by the usage of highly adhesive clamps or a higher clamping force. One disadvantage that comes up with the usage of adhesive clamps is that the adhesive surface must be renewed after each single experiment.

To define the material model on the single wire level for the simulations, a true stress vs. strain curve considering the cross-sectional thinning should be derived from the experimental results. In the experiments, the force vs. elongation curves can be obtained directly using the machine specific software. Since the testing machine is not able to measure the change in the cross-sectional diameter of the specimens, only the engineering stresses $\left(\sigma_{\text {eng }}\right)$ and strains $\left(\varepsilon_{\text {eng }}\right)$ using the initial cross-sectional area can be obtained. However, a true stress vs. strain curve is required for accurate results in the FEA.

The true stress $\left(\sigma_{\text {true }}\right)$ vs. strain $\left(\varepsilon_{\text {true }}\right)$ curve can be converted from the engineering curve, when the true values are calculated approximately with the engineering values of Eqs. (1) and (2) as in [6]:

$\sigma_{\text {true }}=\sigma_{\text {eng }} \cdot\left(1+\varepsilon_{\text {eng }}\right)$

$\varepsilon_{\text {true }}=\ln \left(1+\varepsilon_{\text {eng }}\right)$

According to the Young's modulus of the material and the true stress vs. strain curve, the material model for a single wire can be defined, which is explained in the following.

Material Model The parameters of the material model for a single wire MAT-0 are defined in the LS-DYNA material card *MAT_024:
*MAT_PIECEWISE_LINEAR_PLASTICITY according to [13]. This implements an elastic-plastic material behavior. Parameters and values are listed in Table 3, excluding zeroed parameters.

The load curve LCSS "1" that defines the stress vs. strain derived from the true values in the experiment is implemented as "*DEFINE_CURVE" using the values of Fig. 4.

Simulation Setup In the tensile test situation, the test structure is fixed on one side. A displacement boundary condition implements the tensile load at the free wire end.

The choice of element types influences the calculation results in LS-DYNA, as illustrated in Fig. 5.

The simulations with solid and beam elements lead to the same results for elastic deformation. The mesh of solid elements had elements with edge lengths of $0.02 \mathrm{~mm}$ at the end faces and $0.5 \mathrm{~mm}$ on the cylindrical face of the wire. On the other hand, the length of the beam elements is $0.2 \mathrm{~mm}$. For plastic deformation, the forces of beam elements exceed those of solid elements, as the calculation in the current version of LS-DYNA R11 neglects the cross-sectional deformation for beam elements. Using beam elements saves calculation time by a factor of 6 . However, for more exact results in plastic deformation, the tensile test validation uses solid elements.

\subsection{Bending stress}

The 3-point bending test is realized according to [14]. As preparation, the ends of the HF litz wire were hot crimped

Table 3 *MAT_PIECEWISE_LINEAR_PLASTICITY as material definition of a single wire (MAT-0)

\begin{tabular}{llll}
\hline Parameter & Name of parameter & Value & Unit \\
\hline MID & $\begin{array}{l}\text { Identity Number of Mate- } \\
\text { rial Card }\end{array}$ & 1 & - \\
RO & Mass Density & $8.9 \mathrm{E}-9$ & $\mathrm{t} / \mathrm{mm}^{3}$ \\
E & Young's Modulus & 80,000 & $\mathrm{~N} / \mathrm{mm}^{2}$ \\
PR & Poisson's Ratio & 0.34 & - \\
LCSS & Load Curve ID & 1 & - \\
\hline
\end{tabular}

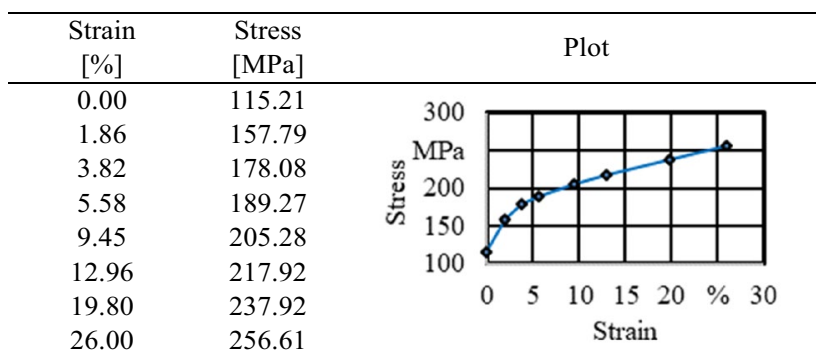

Fig. 4 Values for LCSS axial load curve in *DEFINE_CURVE Stress vs. Strain 


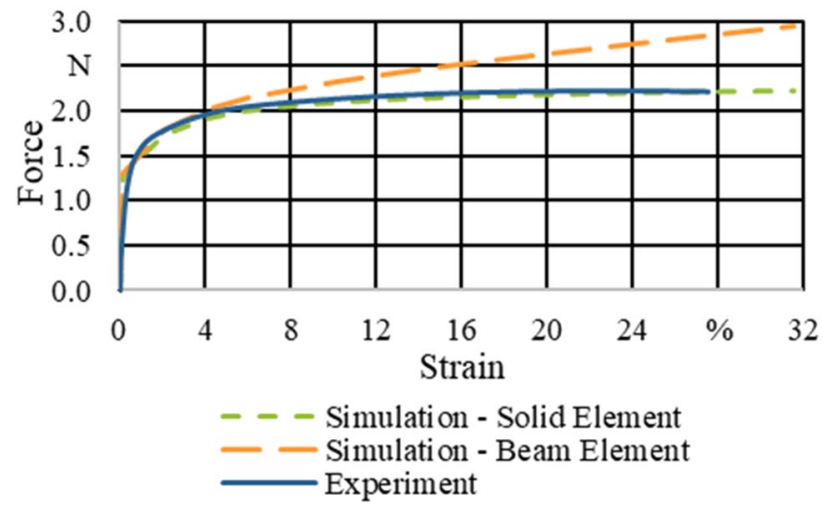

Fig. 5 Comparison of force vs. strain curves of the simulative and experimental tensile test for a single wire

with tubular cable lugs. The force for bending the HF litz wire was measured with a universal testing machine and monitored with the machine specific software.

The geometry model for simulating the bending stress is adapted from the 3-point-bending experiment. The geometry model of the HF litz wire $1740 \times 0.1$ consists of 60 bundles representing the stranded structure with beam elements, three rigid cylinders, a bandage of shell elements and two bonding plates symbolizing the crimped ends of the HF litz wire. The meshed geometry with 14,000 elements and 20,000 nodes is shown in Fig. 6. For the bandage as shell element, the "Belytschko-Tsay" formulation is used.

Material Model Since the bending stress cannot be simulated using the *MAT_024 of the tensile stress, a new material model must be derived. The material behavior of the beam elements is defined by the material card *MAT_029. The *MAT_FORCE_LIMITED material card allows to define the tensile, bending, and torsional behavior independently. As a result, the simulation for the tensile stress could use the same material model as for the bending stress, but as it is shown in Fig. 5 the usage of solid elements together with their specific material model lead to better results for high strain rates. So, the material model for each bundle was systematically derived, starting with an implicit simulation of a single wire, validating it with the explicit LS-DYNA solver. Within the implicit analysis, the material model MAT- 0 is used, that is derived from the FEA of the tensile stress. To develop a material model with *MAT_029, an explicit FEA is executed. The explicit FEA offers advantages in robustness and processing time for nonlinear behavior as e.g. contact nonlinearities [6]. Therefore, the implicit analysis can be used to simulate the single wire. The material model of the explicit FEA is iteratively optimized by validating it with the implicit FEA. Then, the bundle of 29 single wires is simulated and validated with the GAM. As a result, the following parameters for the beam element formulation "Resultant-Belytschko-Schwer Beam" can be defined in the material card, as shown in Table 4. The curve ID 100 defines the material behavior for tensile stress (LC1) (see Fig. 7) whereby the curve ID 101 defines the behavior under bending stress (LPS1, LPT1) (see Fig. 8). All parameters with default values given in the LS-DYNA manuals [13] are not listed.

The load curve LC1 "100" that defines the axial force vs. strain is implemented in the command "*DEFINE_CURVE" using the values of Fig. 7. Those values originate from the tensile stress evaluation of the GAM in LS-PrePost.

Analogous to the tensile stress vs. strain curve, the load curves LPS1 \& LPT1 "101" that define the plastic bending moment vs. rotation strain are implemented in the command

Table 4 Parameters and values for *MAT_FORCE_LIMITED material card for the HF litz wire GAM (MAT-1)

\begin{tabular}{llll}
\hline Parameter & Name of parameter & Value & Unit \\
\hline MID & Identity Number & 1 & - \\
RO & Mass Density & $8.9 \mathrm{E}-9$ & $\mathrm{t} / \mathrm{mm}^{3}$ \\
E & Young's Modulus & 80,000 & $\mathrm{~N} / \mathrm{mm}^{2}$ \\
PR & Poisson's Ratio & 0.34 & - \\
AOPT & Axial Load Curve Option & 0 & - \\
M1-M8 & Applied End Moment & $9.4 \mathrm{E}-1$ & $\mathrm{Nmm}$ \\
LC1-LC8 & Load Curve ID (Axial Force) & 100 & - \\
LPS1/2 & Load Curve ID (Moment vs. Rotation & 101 & - \\
& S-Axis) & & \\
LPT1/2 & Load Curve ID (Moment vs. Rotation & 101 & - \\
& T-Axis) & & \\
\hline
\end{tabular}

Fig. 6 Geometry model for bending stress- $\mathbf{a}$ whole model with bandage and bonding, $\mathbf{b}$ model only with bundles

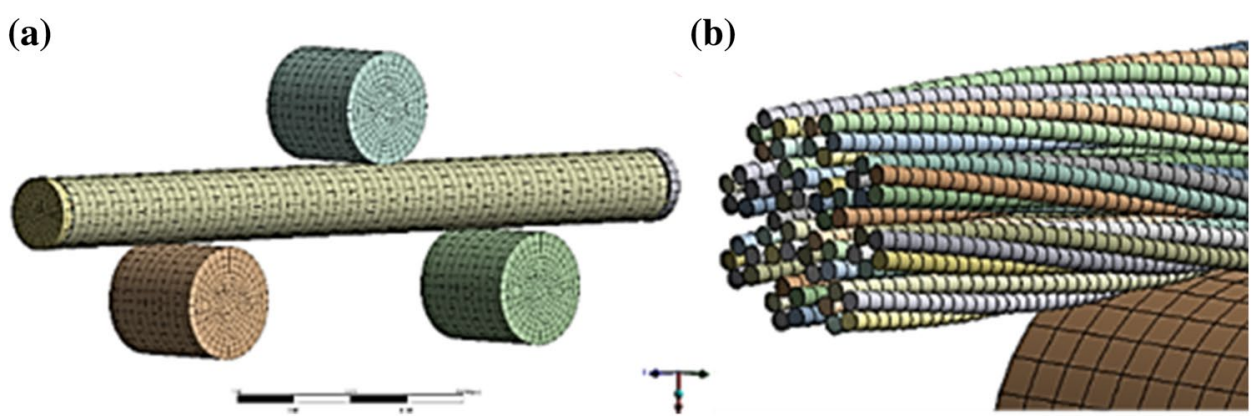




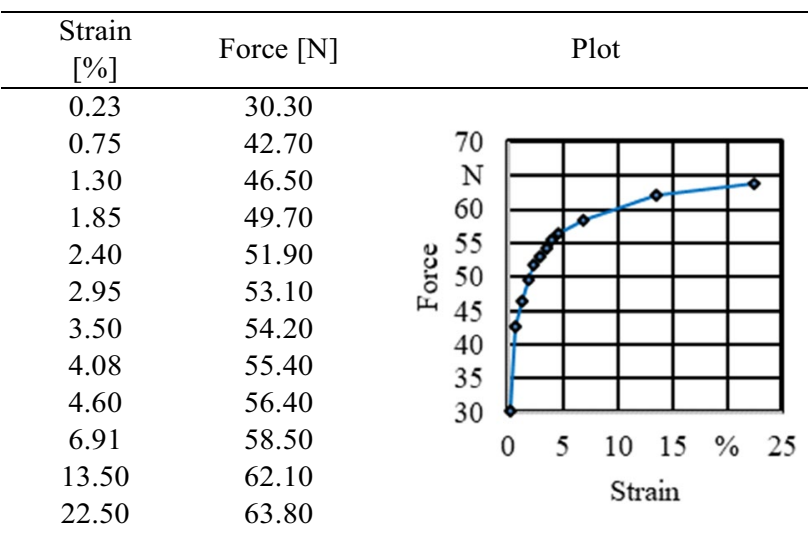

Fig. 7 Values for LC1 load curve in *DEFINE_CURVE-Axial Force vs. Strain

\begin{tabular}{|c|c|c|c|c|c|}
\hline $\begin{array}{c}\text { Rotation } \\
\text { [rad] }\end{array}$ & $\begin{array}{c}\text { Plastic } \\
\text { Moment } \\
{[\mathrm{Nmm}]}\end{array}$ & \multicolumn{4}{|c|}{ Plot } \\
\hline $3.26 \mathrm{E}-05$ & $1.83 \mathrm{E}-02$ & \multirow{2}{*}{$\begin{array}{r}1.0 \\
\mathrm{Nmm}\end{array}$} & & & \\
\hline $3.82 \mathrm{E}-04$ & 2.83E-02 & & & & 2 \\
\hline $7.73 \mathrm{E}-04$ & $3.17 \mathrm{E}-02$ & \multirow{2}{*}{$\begin{array}{r}\mathrm{Nmm} \\
0.8\end{array}$} & & 8 & \\
\hline $1.16 \mathrm{E}-03$ & $3.60 \mathrm{E}-02$ & & & 7 & \\
\hline $1.56 \mathrm{E}-03$ & 4.62E-02 & 苞 0.7 & & 6 & \\
\hline $1.95 \mathrm{E}-03$ & $6.48 \mathrm{E}-02$ & \multirow{4}{*}{ 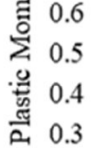 } & 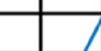 & & \\
\hline $2.34 \mathrm{E}-03$ & $8.56 \mathrm{E}-02$ & & 8 & & \\
\hline $2.75 \mathrm{E}-03$ & $9.56 \mathrm{E}-02$ & & & & \\
\hline $3.12 \mathrm{E}-03$ & $1.03 \mathrm{E}-01$ & & $\angle$ & & \\
\hline $4.76 \mathrm{E}-03$ & $1.39 \mathrm{E}-01$ & 0.2 & & & \\
\hline $9.42 \mathrm{E}-03$ & $2.80 \mathrm{E}-01$ & 0.1 & & & \\
\hline $1.58 \mathrm{E}-02$ & 4.74E-01 & 0.1 & & & \\
\hline $2.22 \mathrm{E}-02$ & $6.66 \mathrm{E}-01$ & \multicolumn{4}{|c|}{$0.000 .010 .02 \mathrm{rad} \quad 0.04$} \\
\hline $\begin{array}{l}2.87 \mathrm{E}-02 \\
3.36 \mathrm{E}-02\end{array}$ & $\begin{array}{l}8.52 \mathrm{E}-01 \\
9.43 \mathrm{E}-01\end{array}$ & \multicolumn{4}{|c|}{ Rotation } \\
\hline
\end{tabular}

Fig. 8 Values for LPS1/LPT1 load curve in *DEFINE_CURVE Plastic Moment vs. Rotation

“*DEFINE_CURVE” using the values of Fig. 8. Those values are evaluated with the GAM, but in this case the rotation of a single beam element and the bending moment of this element is analyzed.

Simulation Setup In the simulation setup, all boundary conditions like the fixed support of the two cylinders, the velocity of the bending punch and the reduced DOFs of the bonding plates are defined. Furthermore, the contacts between the bundles and the bandage respectively the cylinders are defined as frictional contacts using 0.6 as (dynamic) friction coefficient, whereas the contact definition between the bonding plate and the end of the wires is bonded. Body interactions between the bundles are activated.

\section{Validation of simulation results with experiment}

Based on the comparisons between the simulative and experimental results, the geometric models and the simulation results are validated.

\subsection{Tensile stress}

The simulative and experimental results of tensile tests on each bundling level are compared through the force vs. strain curves. The results of comparison for the bundle, strand and litz level using a log-4 scale for the force-axis are shown in Fig. 9, the comparison for a single wire can be derived from Fig. 5.

The simulative results on all four bundling levels conform to the experimental results. However, big deviations in the elastic deformation exist on the strand and litz level. Because hot crimping is used in the tensile experiment to avoid slipping, the stiffness of the material is weakened and the hotcrimped parts on the specimens deform at first, which leads to a softer behavior of the specimens in the experiment. In addition, the distribution of the single wires in the real $\mathrm{HF}$ litz wire is randomly, while in the idealized geometry the

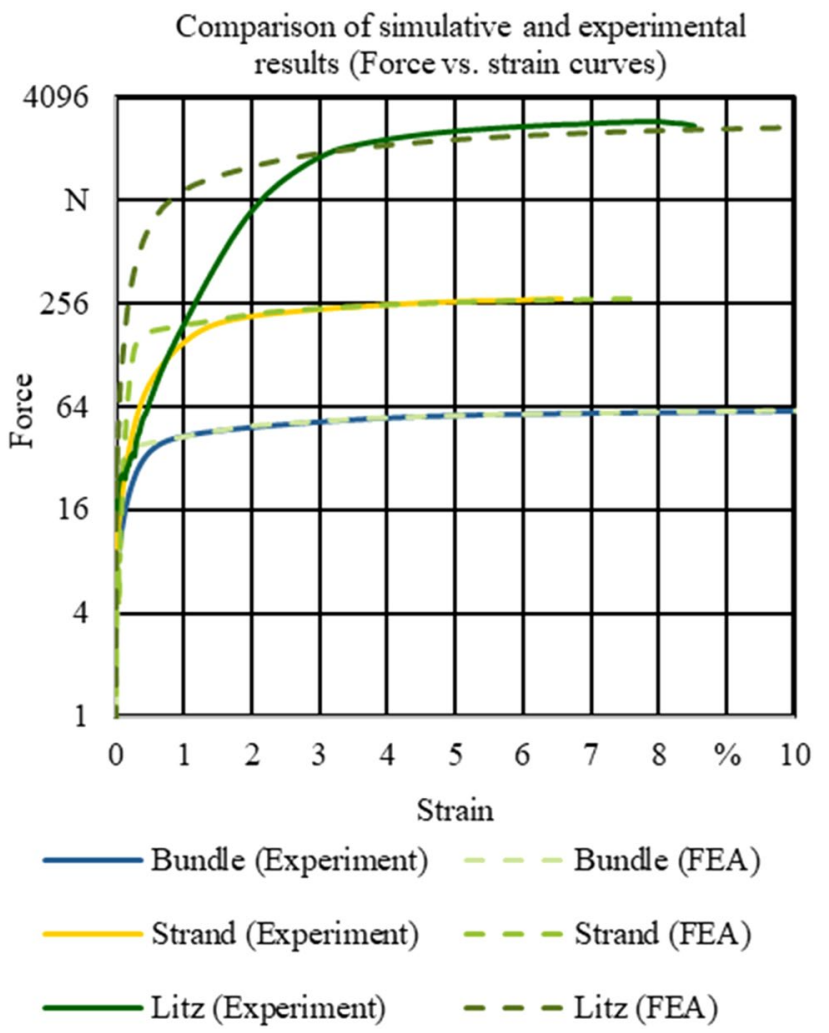

Fig. 9 Comparison of force vs. strain curves of the simulative and experimental tensile tests 
bundles are ideally distributed in the cross-section of the HF litz wire. In consequence, empty spaces exist between the bundles and the packing density is lower. The single wires of the litz under tensile forces move randomly and fill the free space among them, which helps them to avoid the tensile load. However, this phenomenon in the FEA is not as obvious as in the experiments, which make the FEA have a stiffer result than the experiment. Finally, the inaccuracy of the testing machine also has a negative impact on the experimental results. Since the simulations have satisfactory results on the first two bundling levels, the simulations on the strand and litz wire can still be validated.

\subsection{Bending stress}

The Fig. 10 compares the simulation results with the experiment for bending stress. The bending test is executed for four different punch diameters.

The deviation of the results for small bending angles $\left(<50^{\circ}\right)$ can be mainly explained by the idealized geometry of the simulation model, as already known by the tensile stress simulation. The ripples between $90^{\circ}$ and $130^{\circ}$ occur due to the flattening of the structure. The bundles, that are under tensile stress during bending, jump spontaneously trying to reduce the stress. Therefore, it can be monitored an increased bending force at first and then a decreased force after the dislocation of the bundles. The mechanical behavior of the HF litz wire under bending stress can be validated with the chosen simulation setup.

Bending force vs. angle for different punch diameters (Moving average $n=25$ )

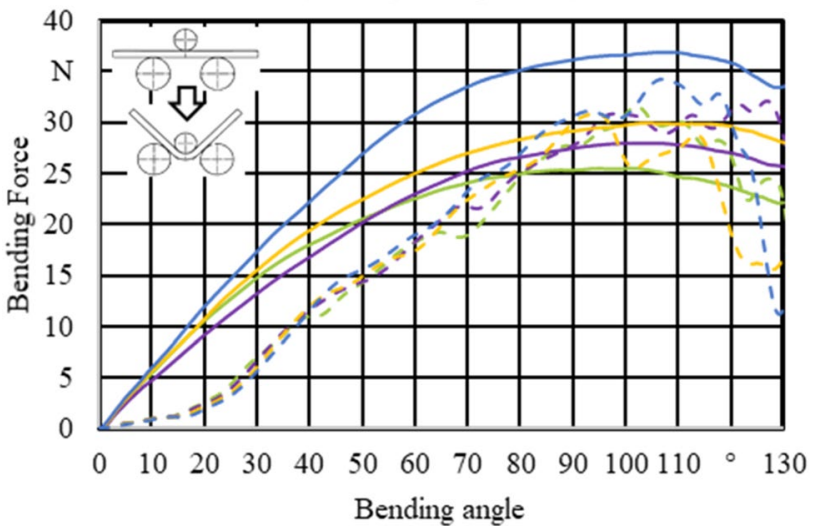

$$
\begin{aligned}
& \longrightarrow \mathrm{D}=10 \mathrm{~mm} \text { (Experiment) } \ldots-\ldots \mathrm{D}=10 \mathrm{~mm} \text { (FEA) } \\
& \longrightarrow \mathrm{D}=8 \mathrm{~mm} \text { (Experiment) - - - } \mathrm{D}=8 \mathrm{~mm} \text { (FEA) } \\
& \mathrm{D}=6 \mathrm{~mm} \text { (Experiment) } \quad---\mathrm{D}=6 \mathrm{~mm} \text { (FEA) } \\
& \mathrm{D}=4 \mathrm{~mm} \text { (Experiment) } \quad-\cdots \mathrm{D}=4 \mathrm{~mm} \text { (FEA) }
\end{aligned}
$$

Fig. 10 Comparison of force vs. angle curves of the simulative and experimental bending test for different punch diameters

\section{Parametric analysis and optimization of HF litz wire under bending stress}

As applications a parametric simulation of different HF litz wire configurations and a simulation of the winding process itself will be explained. The parametric simulation applies to the following parameters: bonding and bandage, pitch length and punch diameter.

\subsection{Bending stiffness evaluation for bonding and bandage}

Figure 11 compares the parameter constellations for bonding and bandage. In four FEAs, all combinations of these parameters are evaluated.

The figure shows that a HF litz wire with bandage has a higher bending resistance momentum due to the higher bending force. The stiffness of the HF litz wire can be increased as well with a bonding, but the main stiffening effect appears due to the bandage. The ripples occur again due to the spontaneous dislocation of the bundles under stress.

\subsection{Bending stiffness evaluation for different pitch lengths}

In addition, the bending force of a bonded HF litz wire without bandage is evaluated for different pitches. With a set of five parameter constellations, the impact of different pitch configurations on the litz level (compare Table 1) in the HF litz wire are simulated. Next to the outer pitch length, also the core pitch is varying. Figure 12 shows the results of the FEA.

A slight increase in the bending force is seen for the reduced pitch length in the core and outer strand to $45 \mathrm{~mm}$.

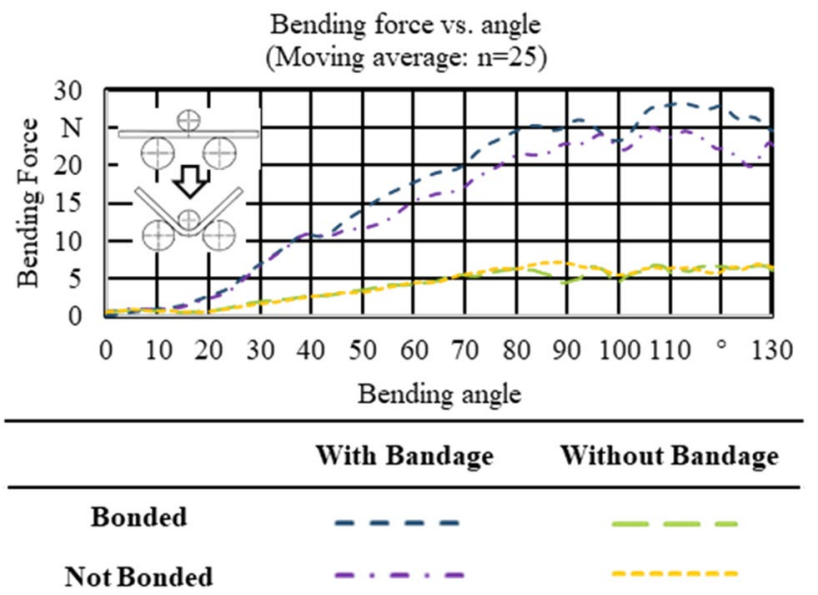

Fig. 11 Comparison of the parameter constellations for bonding and bandage 
Furthermore, selecting different pitch lengths for core and outer strands increases the bending stiffness of a HF litz wire. This is proven by the simulation results of the strand with core pitch lengths of $45 \mathrm{~mm}$ and $37.2 \mathrm{~mm}$ at a lay length of $74.6 \mathrm{~mm}$ for the outer strands. In addition, a strand with a reduced pitch length in the core and outer strand is simulated with pitch lengths of $45 \mathrm{~mm}$ and $37.2 \mathrm{~mm}$, respectively.

\subsection{Spring back evaluation for various punch diameters}

For evaluating the spring back behavior of a HF litz wire, the simulation setup was modified, so that the HF litz wire elastically relaxes after the bending. Thereby bending force and angle is monitored and used for the calculation of the spring back factor $\mathrm{k}$. This factor defines the relation between an offset angle and the elastic spring back angle. The offset angle is defined as the starting position of the elastic relaxation, so when the bending equals zero. The factor $\mathrm{x}$ is defined as unidirectional spring back of the HF litz wire. In Fig. 13, the spring back behavior for four different punch diameters is shown.

The diagram shows a slightly different spring back behavior for different punch diameters. The spring back factors are between 0.93 and 0.95 that equals to a spring back of $5-7 \%$. The spring back for higher punch diameters is higher, because the elastic deformation in relation to the plastic deformation is higher. Higher punch diameters result in less plastic deformation of the HF litz wire.

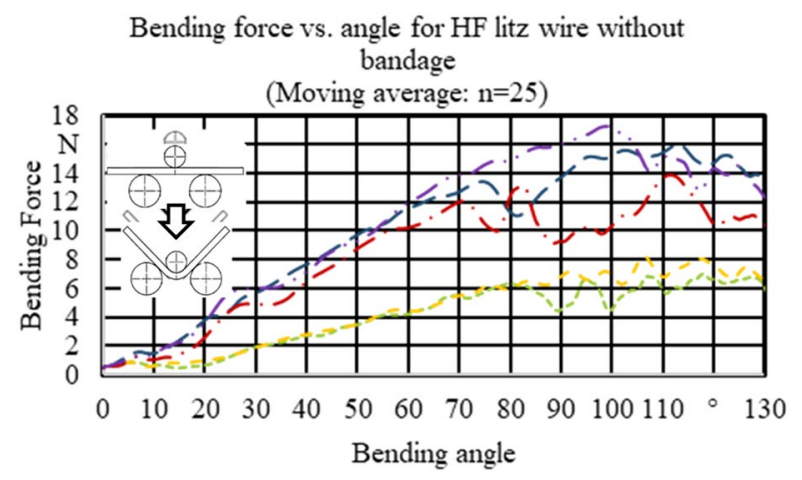

\begin{tabular}{ccc}
\hline & Outer pitch length & Core pitch length \\
\hline$-\cdots$ & $74.6 \mathrm{~mm}$ & $74.6 \mathrm{~mm}$ \\
---- & $45 \mathrm{~mm}$ & $45 \mathrm{~mm}$ \\
--- & $74.6 \mathrm{~mm}$ & $45 \mathrm{~mm}$ \\
$-\cdots-$ & $74.6 \mathrm{~mm}$ & $37.2 \mathrm{~mm}$ \\
$-\cdots-$ & $45 \mathrm{~mm}$ & $37.2 \mathrm{~mm}$
\end{tabular}

Fig. 12 Comparison of the parameter constellations for different pitch lengths
Spring back for different punch diameters of a bonded HF Litz without bandage

(Moving average: $n=25$ )

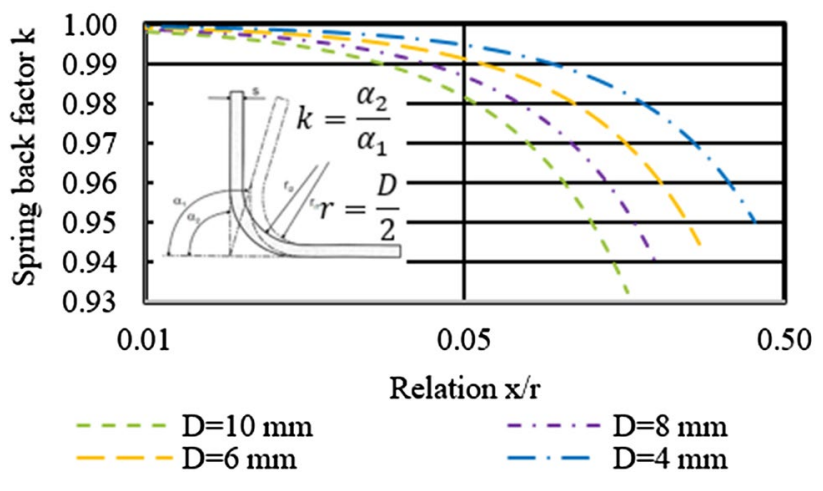

Fig. 13 Evaluation of the spring back for different punch diameters

\section{Dynamic analysis and optimization of the winding process of flat coils}

The simulation of the winding process is realized using the GAM for the HF litz wire with MAT-2, so to utilize a single cylinder geometry with a diameter of $6 \mathrm{~mm}$. Table 5 shows the material parameters of MAT- 2 using the material card *MAT_024 in LS-DYNA. The results are based on the simulative tensile test of the litz wire T3. Parameters with default values given in the LS-DYNA manuals are not listed.

The load curve LCSS "1" that defines the stress vs. strain derived from the true values in the simulative tensile test T3 using the entire structure is implemented in the command “*DEFINE_CURVE" using the values of Fig. 14. After the simulation, the engineering stress and strain can be calculated directly. They are then converted into the true values using Eqs. (1) and (2).

Compared to the Young's modulus of the single wire (80,000 MPa), the Young's modulus of the litz wire GAM (5500 MPa) is significantly lower due to the cavities between the individual wires in the HF litz wire structure (see Fig. 2) in the tensile test T3. However, in the GAM, one homogenous cylinder represents all single wires, and the gaps between them, which leads to less stiffness of the

Table 5 Parameters and values for *MAT_PIECEWISE_LINEAR_ PLASTICITY material card for the HF litz wire GAM (MAT-2)

\begin{tabular}{llll}
\hline Parameter & Name of Parameter & Value & Unit \\
\hline MID & $\begin{array}{l}\text { Identity Number of Mate- } \\
\quad \text { rial Card }\end{array}$ & 1 & - \\
RO & Mass Density & - & $\mathrm{t} / \mathrm{mm}^{3}$ \\
E & Young's Modulus & 5500 & $\mathrm{~N} / \mathrm{mm}^{2}$ \\
PR & Poisson's Ratio & 0.34 & - \\
LCSS & Load Curve ID & 1 & - \\
\hline
\end{tabular}




\begin{tabular}{|c|c|c|c|c|c|c|}
\hline $\begin{array}{c}\text { Strain } \\
{[\%]}\end{array}$ & Stress & \multicolumn{5}{|c|}{ Plot } \\
\hline 0.00 & 29.23 & 120 & & & & \\
\hline 0.54 & 44.97 & $\mathrm{MPa}$ & & & & 0 \\
\hline 0.94 & 54.02 & $\begin{array}{l}100 \\
90\end{array}$ & & & 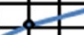 & 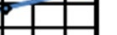 \\
\hline 1.33 & 60.70 & $\approx 80$ & & & & \\
\hline 1.91 & 71.56 & 70 & & & & + \\
\hline 2.66 & 76.71 & $\begin{array}{l}0.00 \\
50\end{array}$ & & & &  \\
\hline 3.58 & 83.40 & 40 & 8 & & & f \\
\hline 5.02 & 91.23 & 20 & L & & & $\square$ \\
\hline 7.12 & 97.98 & & 01 & 23 & 56 & $78 \% 10$ \\
\hline 9.52 & 105.75 & & & & rain & \\
\hline
\end{tabular}

Fig. 14 Values for LCSS axial load curve in *DEFINE_CURVE Stress vs. Strain

GAM compared to the single wire. Figure 15 illustrates the comparison of the force vs. strain curves when utilizing the entire structure with the material model MAT- 0 (see Table 3 and Fig. 4) and the GAM with the material model MAT-2 (see Table 5 and Fig. 14).

After defining the material parameters for the GAM, a simulation model for the winding process of flat coils is defined. The process kinematics represent the winding process defined in Fig. 1 as the most sophisticated and flexible process for flat coil winding.

\subsection{Geometric model}

Figure 16 depicts the geometric assembly. It contains one pressing roller and two guide rollers as well as the coil former. To limit the oscillations of the HF litz wire during the winding process, two dummy guides are also added into the simulation model.

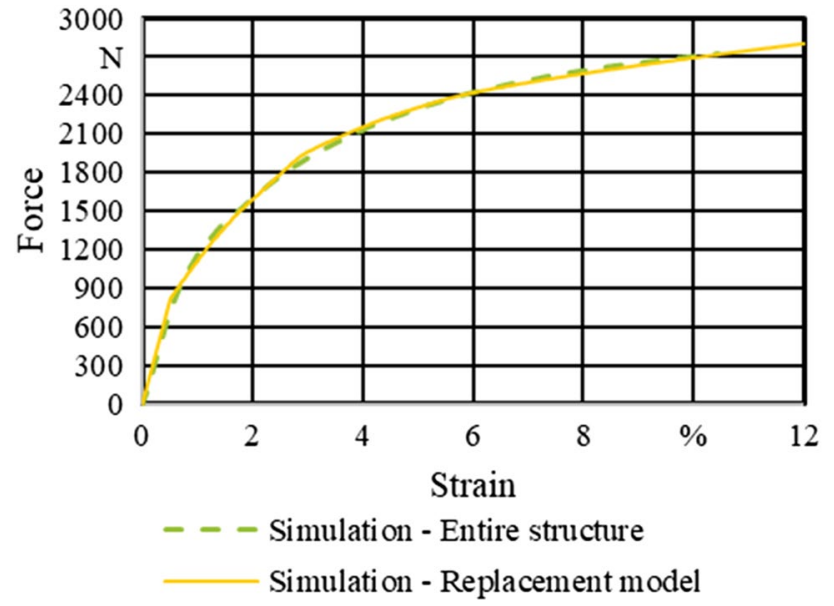

Fig. 15 Comparison of simulative force vs. strain curves of the litz wire model with entire structure using MAT- 0 and the GAM using MAT-2

\subsection{Kinematic model}

The HF litz wire is one sided fixed onto the coil former while the loose end has the wire tensile force inculcated. The aim of the winding process is to place the litz wire onto the coil former. During the winding process, the coil former and the two rollers as well as the dummy guides rotate synchronously around the y-axis of the coil former. The pressing roller presses the litz wire on the coil former through a force on the $y$-axis. A relative movement between the litz wire and the coil former is not desired. The kinematic model of the winding process can be described with three steps:

1. The rollers and dummy guides rotate $90^{\circ}$ synchronously with the coil former around its y-axis.

2. The rollers and dummy guides move backwards by $129 \mathrm{~mm}$ to press the litz wire down on the coil former.

3. The rollers and dummy guides hold shortly afterwards.

These three steps are performed iteratively up to the desired layers of the coil.

In ANSYS LS-DYNA workbench, the rotation of a rigid body can only be defined around its own center of gravity. The boundary condition "Rigid Body Rotation" defines the rotation of the coil former, as it rotates around its own $y$-axis. However, the rotations of the rollers cannot be defined directly, since they do not rotate around their own axes, but also around the $y$-axis of the coil former. Nevertheless, this step can be determined by the boundary condition "displacement" of the bodies, which requires a mathematical analysis for the course of the roller rotation.

\subsection{Simulation model}

The HF litz wire GAM is defined as "flexible" with the related material model MAT-2 (see Table 6). Since the

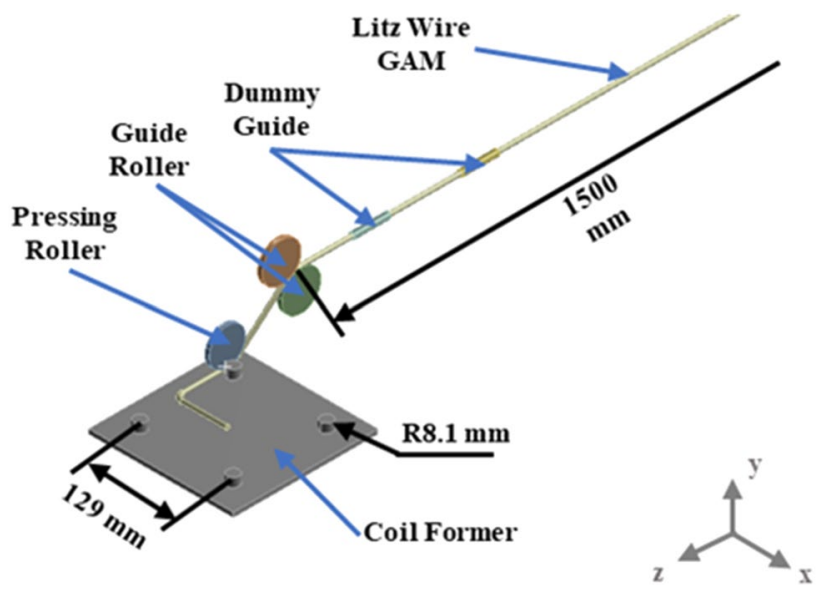

Fig. 16 Geometric assembly of flat coil winding process 
mechanical behavior of the other components is not analyzed in the simulation, they are defined as "rigid".

The contacts between the HF litz wire and the pressing roller as well as the two guide rollers are defined as friction-free. The friction between the litz wire and the two dummy guides is also neglected. The contact between the HF litz wire and the coil former is considered to be frictional with the kinetic coefficient 0.2 . In addition, the fixation of the HF litz wire end side on the coil former is realized by the contact between the surfaces of the HF litz wire end and the upper surface of the coil former, which is defined as a bond. The contacts between the different sections of the HF litz wire in the neighboring layers are defined as frictional by body interactions, where the dynamic coefficient of friction is 0.4 . All components are meshed with 8-nodes hexahedral solid elements. To focus on analyzing the behavior of the litz wire, the geometry of the litz wire GAM is meshed finer than the other "rigid" components, e.g. guides, rollers, or coil former. The simulation model has 71,070 nodes and 54,855 elements in total after meshing.

\subsection{Simulation setup}

To simulate a coil with two layers after the winding process, the end time is determined to be $2.87 \mathrm{~s}$. The "Time Step Safety Factor" is defined to be 0.9. Additionally, Hourglass control through the type "Exact Volume Flanagan-Belytschko Stiffness Form" (LS-DYNA ID 5) with the coefficient 0.1 is also activated. The winding quality, i.e. the positioning accuracy and the change in cross-section of the HF litz wire are analyzed for different tensile forces $(10 \mathrm{~N}, 50 \mathrm{~N}$ and $100 \mathrm{~N})$.

\subsection{Results of the numerical analysis}

The winding process starts from the initial setup (see Fig. 16) and ends after two turns. The top view of the coil former at the end of the simulation is illustrated in Fig. 17a.

For evaluating the winding quality, an evaluation tool is developed in MS Excel. The basic principle of the tool is to retrieve the nodes on the boundaries of cross-sections (CS) in the meshed HF litz wire GAM and to track their coordinates before and after the winding process. As an example, Fig. $17 \mathrm{~b}$ visualizes the actual and nominal positions of the HF litz wire cross-sections after the simulative winding process, when the tensile force on the litz end is $10 \mathrm{~N}$. The observed 600 positions of cross-sections are sampled from the inner to the outer layer and some of them are marked also in Fig. 17b.

\subsection{Analysis of the influence of tensile force on the position deviation}

Figure 18 shows the evaluation of the position deviations under three different tensile forces $F$ on the end of the litz wire.

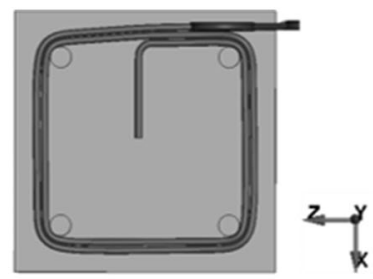

(a)

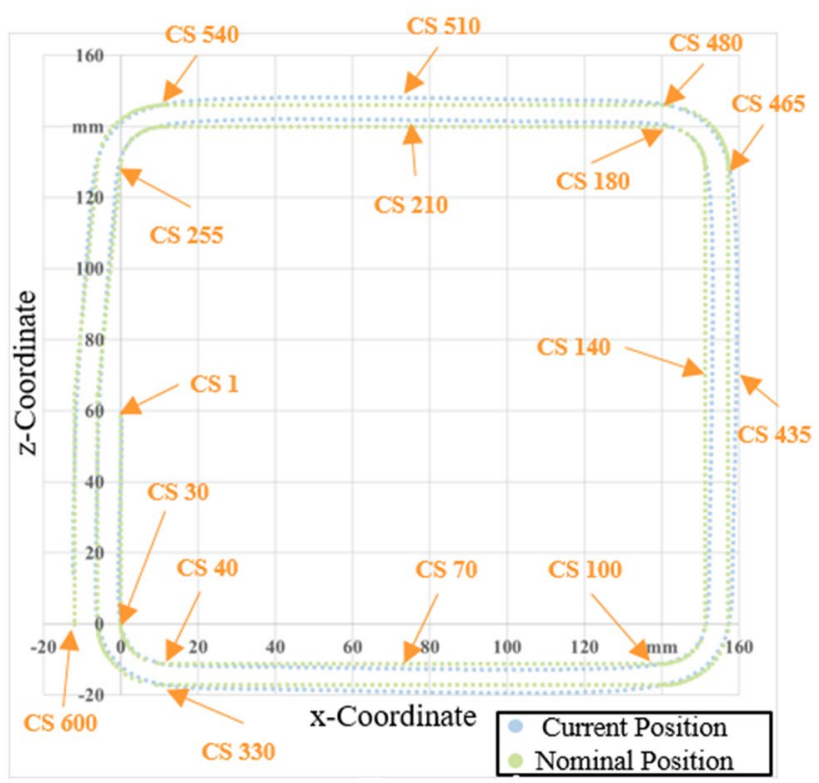

(b)

Fig. 17 Top view of the coil former in the simulation after two turns (a) and example of the evaluation tool (b)

Under all tensile forces, deviations of up to approx. $2.5 \mathrm{~mm}$ occur. The maximum position deviation is always in or near the middle of the straight litz wire sections. In contrast to the others, the sections near the four pins on the coil former have a higher positioning accuracy. The positioning accuracy of the winding process raises with an increasing tensile force on the end of the HF litz wire which is supported by the results seen in [1].

\subsection{Analysis of the influence of tensile and bending force on the diameter}

Furthermore, Fig. 19 compares the smallest distance between two nodes on the outline of each cross-section under different tensile forces.

After the winding process, the HF litz wires cross-section differs for each setup from the initial $6 \mathrm{~mm}$. It is noticeable that the HF litz wire sections near the coil formers are tapered more. This is because all cross-sections with particularly lower diameters correspond to the sections in bending. 


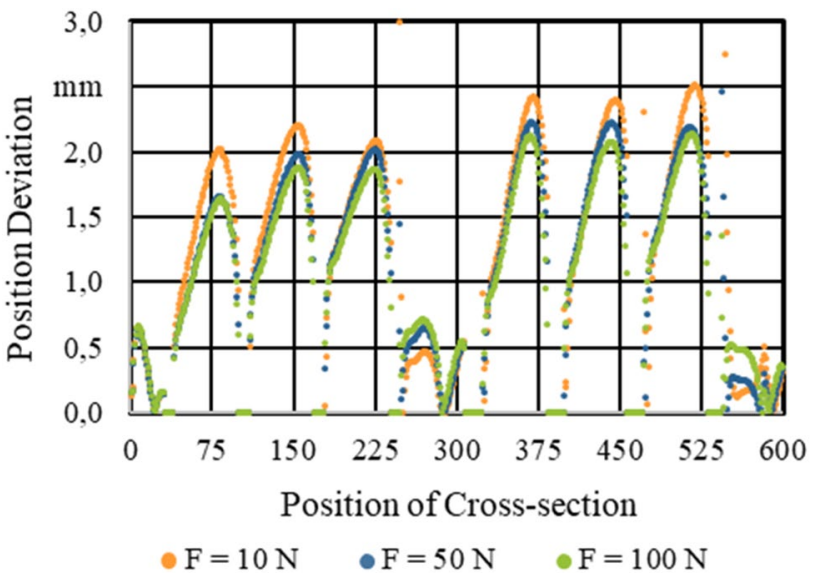

Fig. 18 Evaluation of position deviations under different tensile forces

The tensile force also plays a role here. The higher the tensile force, the more the HF litz wire is loaded and the more the diameters of the cross-sections decrease.

Despite the small stresses at the end of the litz wire, that are a negative side effect of the highly dynamic simulation, the flattening of the HF litz wire's cross-section in the area of the highest stress is characterizing the behavior of the structure under bending stress, as shown in Fig. 20.

The bending decreases the diameter of the HF litz wire as expected and experienced in the experiments.

\section{Conclusions}

Due to the fact, that the mechanical design of twisted multi-wire structures is based on unstructured empirical values, this work focuses on the mechanical simulation

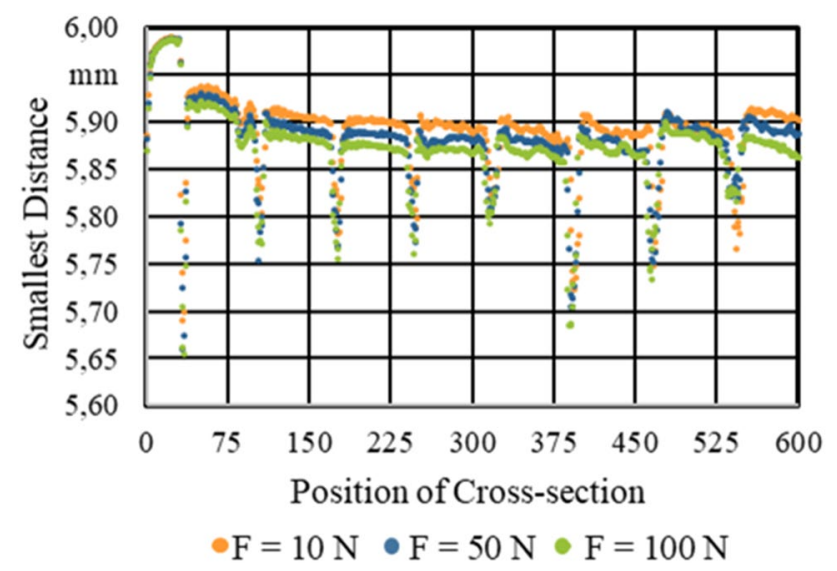

Fig. 19 Evaluation of cross-section diameters under different tensile forces

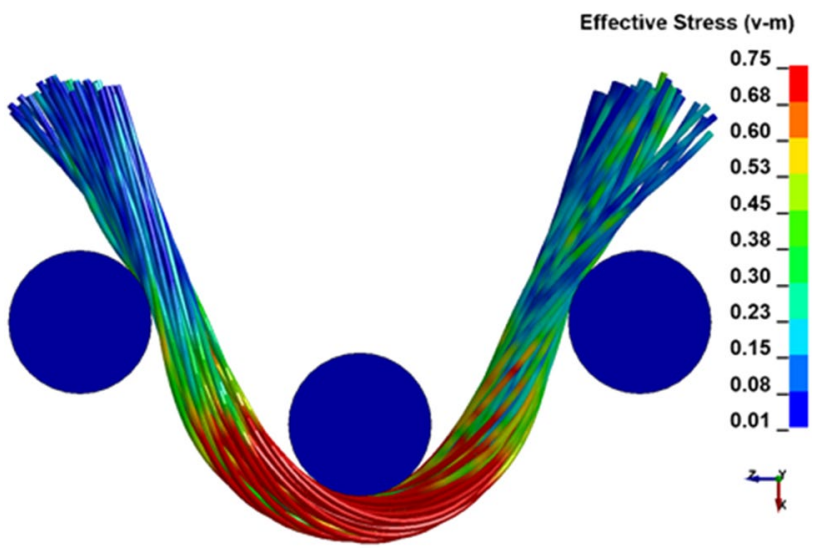

Fig. 20 Cross-section flattening in HF litz wire under bending stress of a twisted multi-wire structure with over 1000 single conductors, like an HF litz wire, under various loads. A systematic approach to a design process, in which FEA is used to support the dimensioning, is developed. Two distinct kinds of mechanical stresses, the tensile and the bending stress on the HF litz wire are successfully modelled virtually and validated with real experiments. The crucial points are the definition of the material parameters for the litz wire GAM, the modelling strategy, and the simulation setup. A validation of the simulation results for HF litz wire under tensile and bending stress has been successfully realized with a comparison of the simulation with real experiments. The mechanical behavior for other configurations of HF litz wire could be simulated, as well as an exemplary winding process, in which the determination of the kinematic model and the evaluation of the simulative results were challenging. These results could be compared with those in the experimental winding process in the future to validate and optimize the simulation model.

Acknowledgements This research project is funded by the German Federal Ministry for Economic Affairs and Energy (BMWi), FKZ01MV18003A. The project is managed by DLR Project Management Agency. The authors are responsible for the content of this publication.

Funding Open Access funding enabled and organized by Projekt DEAL.

Open Access This article is licensed under a Creative Commons Attribution 4.0 International License, which permits use, sharing, adaptation, distribution and reproduction in any medium or format, as long as you give appropriate credit to the original author(s) and the source, provide a link to the Creative Commons licence, and indicate if changes were made. The images or other third party material in this article are included in the article's Creative Commons licence, unless indicated otherwise in a credit line to the material. If material is not included in the article's Creative Commons licence and your intended use is not permitted by statutory regulation or exceeds the permitted use, you will need to obtain permission directly from the copyright holder. To view a copy of this licence, visit http://creativecommons.org/licenses/by/4.0/. 


\section{Appendix}

See Table 6.

Table 6 Comparison of publications dealing with the FEA of stranded structures

\begin{tabular}{|c|c|c|c|c|c|c|c|}
\hline \multirow[t]{2}{*}{ Author } & \multirow[t]{2}{*}{ Application } & \multirow[t]{2}{*}{ Kind of Stress } & \multirow{2}{*}{$\begin{array}{l}\text { Degree of Detail in } \\
\text { Geometry }\end{array}$} & \multirow[t]{2}{*}{ Type of Element } & \multirow{2}{*}{$\begin{array}{l}\text { Number } \\
\text { of single } \\
\text { wires }\end{array}$} & \multicolumn{2}{|l|}{ Number of } \\
\hline & & & & & & Elements & Nodes \\
\hline Boenig [9] & $\begin{array}{l}\text { High-Voltage litz in } \\
\text { automotive area }\end{array}$ & $\begin{array}{l}\text { Bending } \\
\text { Torsion }\end{array}$ & Simplified geometry & Beam, Solid & 1000 & $\begin{array}{l}65,000 \\
45,000\end{array}$ & \\
\hline Hu et al. [8] & $\begin{array}{l}\text { Wire rope for universal } \\
\text { application }\end{array}$ & Tensile & Single wire & Solid & 265 & $\begin{array}{l}1,186,304 \\
1,530,819\end{array}$ & \\
\hline $\begin{array}{l}\text { Usabiaga and Pagalday } \\
\text { [15] }\end{array}$ & $\begin{array}{l}\text { Wire rope for lifting, } \\
\text { mining }\end{array}$ & $\begin{array}{l}\text { Traction } \\
\text { Torsion }\end{array}$ & Single wire & Beam & 49 & - & \\
\hline Weis [7] & $\begin{array}{l}\text { Wire rope in civil } \\
\text { engineering }\end{array}$ & $\begin{array}{l}\text { Tensile, } \\
\text { Bending }\end{array}$ & Single wire & Solid & 265 & $\begin{array}{l}- \\
5,000,000\end{array}$ & \\
\hline Wu and Cao [16] & $\begin{array}{l}\text { Wire rope for universal } \\
\text { application }\end{array}$ & Tensile & Single Wire & Solid & 265 & $\begin{array}{l}- \\
-\end{array}$ & \\
\hline $\begin{array}{l}\text { Zhang and Ostoja- } \\
\text { Starzewski [17] }\end{array}$ & $\begin{array}{l}\text { Single-layered wound } \\
\text { cable }\end{array}$ & Bending & Single Wire & Solid & 7 & $\begin{array}{l}132,584 \\
153,998\end{array}$ & \\
\hline Target state & Universal & $\begin{array}{l}\text { Tensile, } \\
\text { Tensile- } \\
\text { compressive } \\
\text { Bending }\end{array}$ & Single wire & Beam, Solid & $>4000$ & - & \\
\hline
\end{tabular}

\section{Reference}

1. Weigelt M, Masuch M, Mayr A, Seefried J, Kühl A, Franke J (2018) Automated and flexible production of inductive charging systems as an enabler for the breakthrough of electric mobility. In: Schmitt R, Schuh G (eds) Advances in production research. WGP 2018. Springer, Cham. https://doi.org/10.1007/978-3-030-03451 $-1 \_30$

2. Sullivan C, Zhang R (2014) Simplified design method for Litz Wire. In: 2014 IEEE Applied Power Electronics Conference and exposition, APEC 2014

3. Feyrer K, Wehking K-H (2018) FEYRER: Drahtseile. Springer, Berlin Heidelberg (ISBN 978-3-642-54295-4)

4. Risch F (2014) Planning and production concepts for contactless power transfer systems for electric vehicles. Dissertation. Erlangen, 7. April 2014. Bericht aus dem Lehrstuhl für Fertigungsautomatisierung und Produktionssystematik. 253. (ISBN 9783875253696)

5. Hubert M, Weigelt M, Spahr M, Franke J, Hackert J, Mehlhorn M (2016) Explicit finite element analysis for rotary cutting of electrical steel sheet. In: 2016 6th International Annual Engineering Seminar (InAES): IEEE, 1. August 2016-3. August 2016, S. 233-238. (ISBN 978-1-5090-0741-7)

6. Gebhardt C (2018) Praxisbuch FEM mit ANSYS Workbench. Einführung in die lineare und nichtlineare Mechanik. 3., aktualisierte Auflage. München: Hanser, 2018. Hanser eLibrary. (ISBN 9783446450011)

7. Weis JC (2015) Parameterstudie der Kontaktspannungen in zugbelasteten Drahtseilen basierend auf der Finite-Elemente-Methode. Dissertation. Stuttgart, 23. April 2015

8. Hu Y, Hu Z, Ma H, Yan P, Liu Y (2016) Finite element simulation of axial elastic characteristics of wire rope with one round strand layer. In: 2016 IEEE 20th International Conference on Computer Supported Cooperative Work in Design (CSCWD): IEEE, 4. May 2016 - 6. May 2016, S. 16-19. (ISBN 978-1-5090-1915-1)
9. Boenig J (2016) Integration des Systemverhaltens von AutomobilHochvoltleitungen in die virtuelle Absicherung durch strukturmechanische Simulation. Dissertation. Bericht aus dem Lehrstuhl für Fertigungsautomatisierung und Produktionssystematik. 281. (ISBN 9783875254051)

10. Boenig J, Bickel B, Spahr M, Fischer C, Franke j (2015) Simulation of orthocyclic windings using the linear winding technique. In: 2015 5th International Electric Drives Production Conference (EDPC): IEEE, 15. September 2015 - 16. September 2015, S. 1-6 (ISBN 978-1-4673-7511-5)

11. Deutsches Institut für Normung. 6892-1, DIN EN ISO 6892-1. Beuth Verlag, Berlin

12. Schulze G (2010) Die Metallurgie des Schweißens. Springer, Berlin Heidelberg, Berlin

13. Livermore Software Technology Corporation (2018) LS-Dyna Keyword User's Manual Volume II Material Models, 2018

14. Deutsches Institut für Normung. 7438, Metallische Werkstoffe Biegeversuch. Berlin: Beuth Verlag

15. Usabiaga H, Pagalday JM (2008) Analytical procedure for modelling recursively and wire by wire stranded ropes subjected to traction and torsion loads [Online]. Int J Solids Struct 45(21):5503-5520. https://doi.org/10.1016/j.jijsolstr.2008.04.009 (ISSN 00207683)

16. Wu W, Cao X (2016) Mechanics model and its equation of wire rope based on elastic thin rod theory [Online]. Int J Solids Struct. https://doi.org/10.1016/j.ijsolstr.2016.10.021 (ISSN 00207683)

17. Zhang D, Ostoja-Starzewski M (2016) Finite element solutions to the bending stiffness of a single-layered helically wound cable with internal friction [Online]. J Appl Mech. https://doi. org/10.1115/1.4032023 (ISSN 0021-8936)

Publisher's Note Springer Nature remains neutral with regard to jurisdictional claims in published maps and institutional affiliations. 